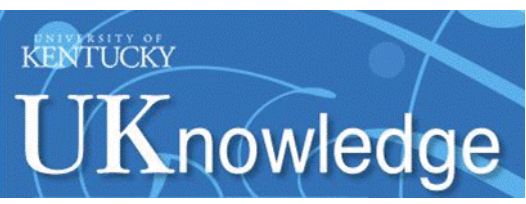

University of Kentucky

UKnowledge

$9-2015$

\title{
Core Beliefs in the Service Leadership Model Proposed by the Hong Kong Institute of Service Leadership and Management
}

\author{
Daniel T. L. Shek \\ University of Kentucky \\ Li Lin \\ Hong Kong Polytechnic University, China
}

Follow this and additional works at: https://uknowledge.uky.edu/pediatrics_facpub

Part of the Pediatrics Commons

Right click to open a feedback form in a new tab to let us know how this document benefits you.

\section{Repository Citation}

Shek, Daniel T. L. and Lin, Li, "Core Beliefs in the Service Leadership Model Proposed by the Hong Kong Institute of Service Leadership and Management" (2015). Pediatrics Faculty Publications. 208.

https://uknowledge.uky.edu/pediatrics_facpub/208

This Article is brought to you for free and open access by the Pediatrics at UKnowledge. It has been accepted for inclusion in Pediatrics Faculty Publications by an authorized administrator of UKnowledge. For more information, please contact UKnowledge@lsv.uky.edu. 
Core Beliefs in the Service Leadership Model Proposed by the Hong Kong Institute of Service Leadership and Management

\section{Digital Object Identifier (DOI)}

https://doi.org/10.1515/ijdhd-2015-0404

\section{Notes/Citation Information}

Published in International Journal on Disability and Human Development, v. 14, no. 3, p. 233-242.

(C) 2015 Walter de Gruyter GmbH, Berlin/Boston

The copyright holders have granted the permission for posting the article here. 
Daniel T.L. Shek* and Li Lin

\section{Core beliefs in the service leadership model proposed by the Hong Kong Institute of Service Leadership and Management}

DOI 10.1515/ijdhd-2015-0404

Received April 7, 2014; accepted June 5, 2014; previously published online August 12, 2015

\begin{abstract}
The service leadership model and related curriculum were developed by the Hong Kong Institute of Service Leadership and Management. To nurture service leadership qualities in university students, a 2-credit service leadership subject was developed at The Hong Kong Polytechnic University. This paper presents the core beliefs and key components of the service leadership model and outlines the content of one of the lectures in the subject. The lecture attempts to help students recognize the importance of leadership competencies, moral character and caring disposition in successful leadership, and to explore ways to develop service leadership qualities. In addition to the lecture, class activities are adopted, including group discussion, role play, self-reflection, and drawing.
\end{abstract}

Keywords: caring disposition; Hong Kong Institute of Service Leadership and Management; leadership competence; moral character; service leadership model.

*Corresponding author: Professor Daniel T.L. Shek, PhD, FHKPS, BBS, SBS, JP, Associate Vice President and Chair Professor of Applied Social Sciences, Department of Applied Social Sciences, The Hong Kong Polytechnic University, Room HJ407, Core H, Hunghom, Hong Kong, P. R. China, E-mail: daniel.shek@polyu.edu.hk; Department of Applied Social Sciences, The Hong Kong Polytechnic University, Hong Kong, P. R. China; Centre for Innovative Programmes for Adolescents and Families, The Hong Kong Polytechnic University, Hong Kong, P. R. China; Department of Social Work, East China Normal University, Shanghai, P. R. China; Kiang Wu Nursing College of Macau, Macau, P. R. China; Hong Kong Institute of Service Leadership and Management, Hong Kong, P. R. China; and Division of Adolescent Medicine, Kentucky Children's Hospital, University of Kentucky, Lexington, Kentucky, USA

Li Lin: Department of Applied Social Sciences, The Hong Kong Polytechnic University, Hong Kong, P. R. China

\section{Introduction}

With industrial transformation and globalization, the service industry has dominated the economic scene of the Hong Kong society, giving rising to an urgent demand for human resources with strong service-oriented qualities [1]. In response to the rising proportion and significance of service industries in contemporary Hong Kong, the Hong Kong Institute of Service Leadership and Management (HKI-SLAM) headed by Po Chung (co-founder of DHL International) developed a service leadership model. To help tertiary institutions in Hong Kong in developing the related curriculum, the Victor and William Fung Foundation funded the Service Leadership Initiative to "develop and produce curriculum and sustainable educational practices that can bring about paradigm shifts in teachers, learners, and citizens' mindsets and frames of reference about leadership, service, and service leadership" [2].

Leadership is often defined in terms of the influence over a group of people. To illustrate, Yukl [3] conceptualized leadership as a process of influence that allows others to understand and accept what to do and how to do it, as well as a process of mobilizing individual and collective efforts to attain shared goals. Northouse defined it as "a process whereby an individual influences a group of individuals to achieve a common goal” [4, p. 3]. In contrast, HKI-SLAM regards leadership as a service in a broader context. Leadership is seen as "a service aimed at ethically satisfying the needs of self, others, groups, communities, systems, and environments", in which service in its definition does not simply aim at the wellness of others, but also involves self-serving efforts aimed at ethically improving one's competencies, abilities, and willingness to help satisfy the needs of others. Furthermore, it conceives service leadership as being "about satisfying needs by consistently providing quality personal service to everyone one comes into contact with, including one's self, others, communities, systems, and environments", while a service leader is viewed as "an on-the-spot entrepreneur who possesses relevant task competencies and is judged by superiors, peers, subordinates, and followers as having 
character and exhibiting care in action situations" [2]. As education is an important vehicle leading to change, the HK-SLAM would like to nurture the service mindset in college students who are going to be leaders. Chung [5] was concerned that universities nowadays delivered less training in "people skills" (e.g. a doctor's comforting an anxious patient) than "product skills" (e.g. a doctor's curing a disease) in professional education. Hence, he strongly called for "restoring respect to service in all forms" (p. 2) in his recent book entitled Service Reborn.

The term "service leadership" is seldom used in the leadership literature. Apart from the SLAM framework, few researchers promote service leadership in service industries. However, their conceptualizations are different from that of the SLAM framework. For instance, Strother and Grönfeldt [6] conceived service leadership as a new paradigm that encourages a collective leadership mindset in service management. Accordingly, service leadership is seen as a culture that "empowers the organization to strategize its promises, design its processes, and engage its people in a proactive quest for competitive advantage" [6, p. 65]. This notion focuses on the needs of customers and also emphasizes the role of leadership as an indispensable part in each employee's work (i.e. everyone can be a leader). Moreover, Schneider et al. [7] regarded service leadership as leadership that entails strong commitment to improving service quality. This kind of leadership fosters a service-focused culture in the organization, which contributes to customer satisfaction and productivity of the organization. However, compared with service leadership within the SLAM framework, these ideologies of service leadership mainly focus on customer service. In brief, service leadership has an objective of "inspiring and sustaining a continual commitment towards achieving a level of service that customers want and for which they are willing to pay" $[8$, p. 3]. Service leadership within the SLAM framework goes beyond customer service, which incorporates and develops many other characteristics of existing models of leadership.

Although only a few leadership models use service leadership as its brand name, the idea of leadership as a form of service is not a novel concept in the literature. Service leadership within the SLAM framework shares with servant leadership in the mindset of leadership that prioritizes service rather than influence over others [9]. Congruent with servant leadership [10], service leadership concerns the needs of the followers, which entails a commitment to the growth of the followers and exerts influence through service. Service leadership within the SLAM framework also integrates characteristics of other extant models of leadership. It emphasizes the possession of morality and caring disposition as a leader, which aligns with the notions of ethical [11], transformational [12], and spiritual leadership [13]. However, service leadership is distinctive from these models of leadership, which is manifested in the seven core beliefs and major principles regarding the determinants of leadership effectiveness. The HKI-SLAM proposed seven core beliefs (CBs), each of which indicates a significant paradigm shift in a frame of reference about leadership.

\section{Seven core beliefs}

CBs that underlie leadership affect leadership behavior, such as decision-making and problem-solving [14]. How leaders think about their leadership role and business operation would also shape their competencies [15]. How a leader thinks largely influences how he/she behaves as a leader. Therefore, in order to develop the service leadership qualities of college students, the initial step is to cultivate a leadership mindset. It is worth noting that HKISLAM allows challenges of the core beliefs. Hence, students are encouraged to discuss their ideas of and share their understanding of each core belief. The seven core beliefs are presented below with elaboration based on the framework of SLAM education [2]. The term "service leadership" mentioned below specifically refers to service leadership within the SLAM framework.

CB1: "Leadership is a service aimed at ethically satisfying the needs of self, others, groups, communities, systems, and environments".

The old paradigm of leadership contends that leadership is a means to "obtaining one's own fame and fortune" or to lead those who are "below" oneself. In contrast, service leadership believes that the basic premise of leadership is to serve. Service is not limited to the traditional service industries such as catering services. Chung [5] defined service as "any activity characterized primarily by human interaction, including interaction via electronic means that satisfies a need" (p. 3). Accordingly, bankers, engineers, lawyers, teachers, and people in all kinds of industries are considered servers. Furthermore, while servant and transformational leadership primarily emphasize serving the wellness of the followers and encouraging people to transcend self-interest for the sake of organization $[15,16]$, respectively, service leadership extends the range of service to three realms: self, others, and systems (e.g. community, society and environment). 
CB2: "Everyday, every human occupies a position of leadership and possesses the potential to improve his leadership quality and effectiveness".

The old paradigm believes that leadership is merely owned by the people who are in a higher position or who have already possessed leadership traits and competences (i.e. top-down leadership). However, service leadership believes that anyone can be a leader or has the potential to be a leader. One could perform numerous service transactions involving leadership acts everyday-ranging from simple self-serving personal improvement (e.g. selfleadership) to complex service activities (e.g. managing an organization). Anyone can practice or improve his/ her leadership skills in these service transactions. For example, a security guard has to help a crowd escape to a safe place when there is a fire. A hall tutor has to persuade a student who attempts to commit suicide to think of the value of his/her life. In sharp contrast to the previous notion that leadership education is only provided for the elite [17], SLAM education is designed for every college student who has the potential to be a leader.

CB3: "Leadership effectiveness is dependent on possessing relevant situational task competencies plus being judged by superiors, peers, and subordinates as possessing character and exhibiting care".

Traditionally, the emphasis is placed on competencies (e.g. management skills) or expertise when delivering leadership education in college students [17]. While the traditional approach is well applicable to an industrial society where the manufacturing industry occupies a central role, it does not apply to a post-industrial society where service industry is booming. In contemporary society, leadership effectiveness does not only depend on power and possession of relevant task competencies, but also focuses on the leader's moral character and caring disposition judged by the followers or service recipients. The basic assumption is that service-provider (i.e. server) himself/herself is the service. This core belief is in line with the extant literature documenting that a customer's perception of a service provider's moral behavior (e.g. ethical sales behavior) [18] and caring disposition (e.g. empathy) [19] positively influences the customer's trust in that service provider, further influencing customer loyalty or commitment. It also echoes the research indicating the important role of morality and caring behavior in followers' trust in leaders and leadership effectiveness [20-22]. HKI-SLAM calls for equal or even stronger emphasis on cultivating moral character and nurturing caring disposition among college students, in addition to the existing training in competencies.
CB4: "Service includes self-serving efforts aimed at ethically improving one's competencies, abilities, and willingness to help satisfy the needs of others".

Servant leadership conceptualizes service as other-oriented activity that satisfies the needs of others $[9,10]$. In contrast, service leadership additionally believes in the importance of serving oneself by self-leadership. Chung [5] believed that "a leader is unable to optimize his or her ability to lead others well unless he or she is healthy in mind, body, and spirit". In order to provide high quality service, endeavor of self-improvement should be made including nurturing developmental assets as well as preparing oneself to serve the needs of others. Specifically, this self-improvement accumulates resource for one to serve and to lead others, which includes the following:

- Service competencies (knowledge, skills, values, and attitudes);

- Leadership competencies (knowledge, skills, values, and attitudes);

- Domain-specific competencies (specialized knowledge and skills);

- Character strengths (virtuous thinking and behavior);

- Physical, mental, and spiritual health;

- Social networks (family, loyal friends, allies);

- Material resources (wealth and prestige items); and

- Willingness (prosocial values, attitudes, and behavior).

This notion is in contrast to the traditional leadership models that simply assume that individuals inherit the socalled desired leadership traits (e.g. personality, motive, skills, values), which are not owned by others; hence they do not need to improve [3, 23]. Many contemporary researchers challenged this inherent or trait-like perspective of leadership. They regarded leadership as a process or re-interpreted trait of leadership as malleable [4, 24, 25]. HKI-SLAM also shares the incremental perspective and calls for lifelong endeavor to improve one's competencies, abilities and willingness to serve. In addition, HKI-SLAM believes that self-improvement is not only a service for leaders themselves, but also prepares leaders to provide quality service to others.

CB5: "Service leadership is about consistently providing high quality personal service to everyone that one comes into contact with, including one's self".

Similar to CB3, a leader's competence, character, and caring disposition perceived by followers or servicerecipients largely influence the latter's perception of quality of service and effectiveness of leadership, because 
it may boost or dampen loyalty and commitment towards the leader. Authority figures or powerful persons who display behaviors that undermine the well-being of subordinates or customers cannot effectively lead others. Therefore, a leader must consistently provide high quality service to each person he/she encounters. Consistency is important because trust in leaders is accumulated over time through the past satisfactory services (reliability and trustworthiness). Moreover, despite an acknowledged requirement of high quality in service provision, traditional service provision is about delivering "one-size-fitsall" service to customers. In contrast, personal service proposition that fits each individual that one interacts is highlighted in the SLAM framework.

CB6: "Service leadership is the world's oldest, most competitive, and longest surviving business model".

Though the term "service leadership" is rarely documented in the extant literature, the idea of service leadership is not invented nowadays. According to the SLAM framework, collaborative service-focused thinking and action is the world's oldest and longest surviving competitive group model. In the remote era, human beings have evolved an innate "moral intuition" and an instinctive disposition to serve, which has enhanced the likelihood of collective survival afterwards [26-27]. However, HKISLAM pointed out that the innate moral intuition was undermined during the industrial age. As goods-based business models overrode service-focused thinking and behavior over the past years, it is high time to re-establish the education of college students with regard to relevant moral character and caring disposition.

CB7: "High-paying, high status leadership positions and management promotions will go to people who have domain-specific knowledge and skills plus service leadership competencies, character strengths, and a caring social disposition".

In the industrial era, people who were productive in manufacturing enjoyed high income and position. Nonetheless, in the post-industrial era in which the service-oriented industry is rewarded, college graduates who are equipped with expertise and service leadership qualities (competencies, character and caring disposition) will have highpaying jobs, high-ranking administrative positions, or promising promotional prospects in their organizations. On the one hand, "personal prosperity in Hong Kong is influenced by one's ability to provide quality service to all of the people one comes into contact with" [2]. On the other hand, there are monetary and spiritual benefits of being a service leader.

\section{Major components of service leadership $\left(E=M C^{2}\right)$}

According to the SLAM framework, competencies of leadership, moral character, and caring disposition are regarded as three major components that determine leadership effectiveness (i.e $\mathrm{E}=\mathrm{MC}^{2}$ ). This formula suggests the inevitable role of competencies, moral character, and caring disposition in determining leadership effectiveness. More importantly, HKI-SLAM adopts an incremental mindset [28] regarding the the determinants of leadership effectiveness, which asserts that these attributes are malleable and can be improved. Therefore, it is possible, and even necessary, to nurture students to be competent, moral, and caring when practicing leadership.

First, an effective service leader possesses multiple leadership competencies. According to competency models, competency refers to specific knowledge, skills, abilities, and characteristics required to perform a role effectively in a given organization [29]. There are four typical categories of competency of leadership [24]: 1) intrapersonal competency (e.g. emotional regulation), 2) interpersonal competency (e.g. building and maintaining positive social relationship), 3) business competency (e.g. coordination and operation), and 4) leadership competency (e.g. empowering a group of people). Notwithstanding numerous competencies being regarded as vital to leadership [24, 30], HKI-SLAM believes in the importance of three distinctive types of competencies [2], namely, service competency, leadership competency, and task competency. Service competency pertains to the readiness, willingness, and capacity to offer the most appropriate and satisfactory service in a particular context. Leadership competency refers to the capacity of using appropriate and satisfying ways to lead people to achieve a personal or a group goal, to solve a social problem, or to satisfy a specific need. Aside from the capacity to lead others, leadership competency includes abilities of leading oneself to improve one's readiness, willingness, and capacity to satisfy the needs of others. Finally, task competency denotes the possession of adequate expertise knowledge, skills, values, and attitudes to perform a task or satisfy a need in a certain context.

Aside from competencies, moral character and caring disposition are perceived as important determinants of leadership effectiveness. Service leadership contends that people with moral character and a caring disposition are generally friendly and trustworthy, or at least non-threatening. The leaders who lack moral character or caring disposition can hardly develop strong, positive social 
relationships. Leaders with moral character can differentiate what is right from what is wrong and then act ethically based on such judgment. Meanwhile, leaders having a caring disposition concern themselves with wellness of self, others, groups, and systems, which are under their influence.

Possession of moral character and caring disposition has been identified as characteristics of other leadership styles despite their distinctive emphases. Spear [31] distinguished ten essential characteristics of servant leadership, which include listening (i.e. communicating and seeking to identify others' need) and empathy (i.e. standing in others' shoes) that indicate caring of followers. According to Russell and Stone [32], honesty and integrity, credibility and trust must be highlighted, as these reflect the moral character of leaders. Similarly, in van Dierendonck's [10] summary of servant leadership characteristics, the moral character of authenticity, which refers to acting consistently with one's inner thoughts and feelings, is highlighted [33]. Transformational leaders also care about and observe moral code. Transformational leaders have to serve as role models who are admired, respected, and imitated by followers; thus, they should demonstrate moral character, such as integrity [34]. They also show individual consideration toward followers, which encompasses the concern for and acceptance of individual needs and differences. Morality and care are also highlighted as desirable characteristics of, but not limited to, ethical leadership [11], spiritual leadership (e.g. altruistic love) [13], and authentic leadership [35].

Empirically, the leadership style incorporating moral character and caring disposition showed abundant positive follower outcomes (e.g. follower motivation and satisfaction with leaders) and leader outcomes (e.g. leadership effectiveness) [10, 11, 36, 37]. Specifically, extant research has suggested that the caring behavior and moral character of leaders themselves are associated with plenty of positive leadership outcomes [20-22, 38]. To illustrate, leadership empathy and leaders' ethical values uniquely predicted heightened quality of leader-member exchange (high quality involving trust, liking, and respect) through relations-oriented behavior (e.g. providing psychological support to followers or developing their skills) [20]. Given the significance of moral character and caring disposition in leadership effectiveness, it is important to arouse student concern over these attributes, in addition to developing their leadership competencies.

In short, at the beginning of service leadership education, students should be aware of the beliefs and values of service leadership. Instilling a mindset of service is important in developing leadership traits [39]. Through embracing and internalizing the beliefs and values of service leadership, students would be motivated and willing to provide service that satisfies one's needs and those of others and the system to which they belong. Therefore, this lecture is designed to provide students with a basic understanding of the seven core beliefs and major assertions of the SLAM framework, with specific reference to the three major components (competencies of leadership, moral character, and caring disposition) in effective service leadership.

\section{Lecture content}

"To serve others before ourselves" is the central idea of service leadership. Serving others provides a means by which a leader empowers others to accomplish the collective goals. In this lecture, the seven core beliefs of service leadership are introduced. The major components of effective service leadership are also explained.

There are several intended learning outcomes of this lecture. After this lecture, students will be able to: (a) understand the seven core beliefs about service leadership; (b) appreciate the key components of effective service leadership $\left(\mathrm{E}=\mathrm{MC} \mathrm{C}^{2}\right.$; (c) recognize the importance of leadership competencies, moral character and caring disposition in successful leadership; and (d) explore ways to develop leadership competences, moral character, and caring disposition.

In this lecture, class activities, including group discussion (role play), self-reflection, and drawing are used in addition to lecture. The lecture plan is presented below in Table 1.

The lecture begins with a warm-up activity to draw students' attention to the nature and features of quality service. Two pieces of news concerning unqualified service are presented (Appendix 1). The first piece describes a doctor who is suspended practice due to misleading advertisements. The second reports a cooking oil company that is found selling products containing carcinogenic substance. Students are asked to identify any bad service involved and provide relevant reasons. The teacher also guides students in formulating a criterion for good service in the respective cases. Students are reminded that both the doctor and the cooking oil company take a leading role in their respective fields but have shown ineffective leadership. The teacher wraps up the warm-up activity by introducing the lecture theme.

In the first part of the lecture, the key knowledge point presented comprises the seven core beliefs in service 
Table 1: Lecture plan.

\begin{tabular}{ll}
\hline & Teaching content \\
\hline $\begin{array}{l}\text { Part 1: Definitions and theories of service leadership (including the } \\
\text { seven core beliefs) }\end{array}$ & - Lecture \\
& - Warm-up activity: "Good service vs. Bad service?” \\
Part 2: Major components of service leadership & - Role play: "Do you understand the core belief?” \\
Part 3: Importance and consequence of service leadership & - Lecture \\
Part 4: Conclusion & - Drawing activity: "Draw it out” \\
\hline
\end{tabular}

leadership. Introducing the seven core beliefs, the teacher asks questions to prompt students' thoughts about the subject matter. In order to contrast the traditional paradigm with the service leadership paradigm, we prepare two sets of questions (Table 2). We first ask a question that prompts students to think about the paradigm of leadership (i.e. old paradigm question). Then we clarify the questions and emphasize the paradigm shift of leadership. Afterwards, we ask another question to deepen students' understanding of the core beliefs (i.e. new paradigm question).

To illustrate, before introducing CB1 (i.e. "Leadership is a service aimed at ethically satisfying the needs of

Table 2: The questions used in teaching seven core beliefs.

\begin{tabular}{|c|c|}
\hline Core beliefs & Questions \\
\hline $\begin{array}{l}\text { Core belief } 1 \\
\text { Leadership is a service aimed at ethically satisfying the needs of } \\
\text { self, others, groups, communities, systems and environments. }\end{array}$ & $\begin{array}{l}\text { Old paradigm question: What does a leader look like? Like a king } \\
\text { having many people serving round him/her? } \\
\text { New paradigm question: What kind of service can a leader provide? }\end{array}$ \\
\hline $\begin{array}{l}\text { Core belief } 2 \\
\text { Everyday, every human occupies a position of leadership and } \\
\text { possesses the potential to improve his/her leadership quality } \\
\text { and effectiveness. }\end{array}$ & $\begin{array}{l}\text { Old paradigm question: Can I be a leader? } \\
\text { New paradigm question: Can you identify any personal acts of } \\
\text { leadership you performed in the past week? } \\
\text { Where (individual, family, school, community)? }\end{array}$ \\
\hline $\begin{array}{l}\text { Core belief } 3 \\
\text { Leadership effectiveness is dependent on possessing relevant } \\
\text { situational task competences plus being judged by superiors, peers, } \\
\text { and subordinates as possessing character and exhibiting care. }\end{array}$ & $\begin{array}{l}\text { Old paradigm question: Will people accept my leadership? } \\
\text { New paradigm question: Do you think it is important to possess } \\
\text { character and demonstrate care for a leader in your professional } \\
\text { field (e.g. Engineering, IT, Science, etc.)? }\end{array}$ \\
\hline $\begin{array}{l}\text { Core belief } 4 \\
\text { Service includes self-serving efforts aimed at ethically improving } \\
\text { one's competences, abilities, and willingness to help satisfy the } \\
\text { needs of others. }\end{array}$ & $\begin{array}{l}\text { Old paradigm question: Am I ready to be a leader? } \\
\text { New paradigm question: Do you think it is important to improve } \\
\text { the self? } \\
\text { How often do you seek ways to reflect on and improve yourself? }\end{array}$ \\
\hline $\begin{array}{l}\text { Core belief } 5 \\
\text { Service leadership is about consistently providing high quality } \\
\text { personal service to everyone that one comes into contact with, } \\
\text { including one's self. }\end{array}$ & $\begin{array}{l}\text { Old paradigm question: Can I provide service regardless of quality? } \\
\text { New paradigm question: What kind of service is a high quality } \\
\text { service provided by leaders in your professional field? }\end{array}$ \\
\hline $\begin{array}{l}\text { Core belief } 6 \\
\text { Service leadership is the world's oldest, most competitive, and } \\
\text { longest surviving business model. }\end{array}$ & $\begin{array}{l}\text { Old paradigm question: Is Service Leadership a new model? } \\
\text { New paradigm question: Does Service Leadership enhance the } \\
\text { survival of cooperative group? }\end{array}$ \\
\hline $\begin{array}{l}\text { Core belief } 7 \\
\text { High-paying, high status leadership positions and management } \\
\text { promotions will go to people who have domain-specific } \\
\text { knowledge and skills plus service leadership competencies, } \\
\text { character strengths, and a caring social disposition. }\end{array}$ & $\begin{array}{l}\text { Old paradigm question: Who can get higher payment and higher } \\
\text { position? } \\
\text { New paradigm question: What kind of job you want to take after } \\
\text { graduation? } \\
\text { In order to take that job, which component of Service Leadership } \\
\text { you need to improve? }\end{array}$ \\
\hline
\end{tabular}


self, others, groups, communities, systems and environments"), we ask students what a leader looks like and if he/she acts like a king having many people serving around him/her. Contrasting with this typical image of a leader, we highlight that service leaders prioritize serving others' needs. To help students differentiate a service-provider from a service-leader, we guide them to think of what kind of service (e.g. managing the organization) a leader must provide in the "new paradigm question". Another knowledge point worth highlighting is that there are three realms of service, namely, self, others, and systems. Contrasting with the traditional concept of service that targets at others, HKI-SLAM believes service can be provided for the self, others, and systems.

For CB2 (i.e. "Everyday, every human occupies a position of leadership and possesses the potential to improve his/her leadership quality and effectiveness"), there are two main points to be conveyed to the students. The first is that everyone can be a leader. The second views that service transactions range from simple (tutoring a younger relative) to complex (e.g. managing a country) and people can practice leadership in these service transactions. Students are invited to identify their personal acts of leadership in daily life; this activity heightens their awareness of daily leadership behavior and helps them strengthen their efficacy to be a service leader.

For CB3 (i.e. "Leadership effectiveness is dependent on possessing relevant situational task competences plus being judged by superiors, peers, and subordinates as possessing character and exhibiting care"), there are two main knowledge points. First, there are three determinants (i.e. leadership competencies, moral character, and caring disposition) influencing leadership effectiveness. Second, service leadership places stronger emphasis on strengthening leaders' moral character and caring disposition. As moral character and caring disposition are not salient leadership characteristics in some professions (e.g. engineering, science, information technology), the teacher guides students to consider if this core belief also applies to leaders in these professions.

For CB4 (i.e. "Service includes self-serving efforts aimed at ethically improving one's competences, abilities, and willingness to help satisfy the needs of others"), two main knowledge points are illustrated. First, service leaders provide service for themselves, including selfimprovement. Second, service leaders need to improve their competencies, abilities, and willingness to help satisfy the needs of others, with more elaboration in the aspect of willingness.

For CB5 (i.e. "Service leadership is about consistently providing high quality personal service to everyone that one comes into contact with, including one's self"), two knowledge points are explained. First, consistency and high quality of service are highlighted as they influence the recipients'/followers' judgment, loyalty, and commitment towards leaders. Next, high quality service may vary across professions. Although some characteristics (e.g. trustworthiness, problem-solving skills) are necessary for leaders in different occupations, each profession has its unique requirement and context. As such, students are guided to imagine what the high quality service delivered by a leader looks like in their aspiring profession.

For CB6 (i.e. "Service leadership is the world's oldest, most competitive, and longest surviving business model"), it is emphasized that service leadership is adaptive because it enhances the survival of the cooperative group.

For CB7 (i.e. "High-paying, high status leadership positions and management promotions will go to people who have domain-specific knowledge and skills plus service leadership competencies, character strengths, and a caring social disposition"), two major knowledge points are noteworthy. First, high salary and position belong to those who have service leadership competencies, character, and care. Next, there are monetary and spiritual benefits for a service leader.

In order to facilitate students' understanding of the core beliefs, we invite them to roleplay the core beliefs (see Worksheet 1). Specifically, each group is assigned to demonstrate a core belief. Students discuss with their group members to find an example that best illustrates that core belief. We then invite students to act out the core belief under focus. This activity helps students visualize the abstract concept and relate it to daily life. The teacher rounds up by concluding that each core belief can be applied to real life situations.

The second part of the lecture mainly illustrates the major components of service leadership $\left(E=M C^{2}\right)$. However, as this is the beginning phase of acquiring these three influential components of service leadership, our goal is to provide students with a basic understanding of what competencies, moral character, and caring disposition are.

A drawing activity is also utilized to facilitate students' understanding of these three components. The teacher assigns each group with one component and asks them to draw a picture accordingly. Students can draw any image that comes to mind in relation to the target component. They will then share their pictures and explain their understanding of the component based on their drawings. 
The third part of the lecture illustrates the importance and consequence of service leadership. Two knowledge points are noted here. The first one highlights the atmosphere of organization where all people are service leaders, while the second emphasizes the mutual influence exercised by service leaders and their followers.

This lecture aims to highlight the core beliefs and basic assertions of the service leadership model. In the last activity, the teacher asks students to reflect on themselves including their values, aspiring profession, strengths, and weaknesses that would influence their pursuit of a career (see Worksheet 2). This activity helps students gain a better understanding of themselves so that they would have a clearer idea of what they need to learn and improve in the future. This lecture is ended by sharing an image of a service leader-a person with a brilliant brain, a warm heart, and excellent moral character.

\section{Conclusion}

This lecture is designed to increase students' understanding of the basic concepts and assertions of the service leadership model developed by the Hong Kong Institute of Service Leadership and Management. Specifically, the seven core beliefs and three major components of effective service leadership are presented. This lecture provides a theoretical framework that guides students' further learning of the concept of service leadership. Afterwards, the lectures will continue to illustrate each core belief and nurture students' development with respect to the three major components of service leadership.

Acknowledgments: The service leadership research project at The Hong Kong Polytechnic University is financially supported by the Victor and William Fung Foundation.

\section{Appendix 1}

- News 1: Doctor has been suspended practice over misleading advertisements.

A doctor has been suspended for 8 months after the Medical Council found him guilty of making misleading claims over the promotion of beauty treatment. Michael Yam arrived at the Medical Council this afternoon for the verdict. Yam was found guilty of 16 counts of professional misconduct. The council heard that Yam helped establish local beauty centres, I-Sky Beauty as well as Medical and Phototherapy Beauty Centre. He actively helped to promote these centre services and products in magazines, radio programmes, leaflets, and advertisements between 2008 and 2010. The council found that the benefits of the promoted items were exaggerated and some were even false.

Source: Pearl News 730 - Jan 02, 2013.

- News 2: Cooking oil from Beidahuang company has been found containing cancer-causing substance.

Two samples of cooking oil taken from Beidahuang Oil and Fat (Hong Kong) Limited in Tuen Mun were found to contain the cancer-causing substance, benzopyrene. The level exceeds safety standards on the mainland and in the European Union. Beidahuang said they did not import the oil but was just doing the packaging for customers. Health authorities are trying to trace the source of cooking oil that has been found to contain the cancer-causing substance. Samples of the oil were taken from factories in Tuen Mun and Kwai Chung. But they obtained certification from the customer which showed that the oil is suitable for human consumption.

Source: Pearl News 730 - Dec 19, 2012. 
Worksheet 1 (sample)

\section{Do you understand the belief?}

Core Belief 2:

Everyday, every human occupies a position of leadership and possesses the potential to improve his/her leadership quality and effectiveness.

1. Based on your knowledge or past experience, think of scenarios that can appropriately reflect this belief.

2. Discuss with your group members and act out the scenarios.

Please note that you can write a script to narrate the story. For the students who act out the scenarios, you can use body language only to show the scenarios. Please do NOT use the word "service" in your script. Other classmates will guess the belief from your performance.

Worksheet 2

Will I become a SERVICE LEADER

Do you want to be a successful leader in your future career field? The premise is that you have to understand yourself first.

How could you lead others without understanding yourself?

The following questions will help you understand yourself better.

1. To you, what are the most important values and principles?

2. What do you want to be after graduation?

3. What personal strengths do you possess that will help you achieve your goals (e.g., knowledge, skills, personality, spirit, etc.)?

4. In regard to $\mathrm{E}=\mathrm{MC}^{2}$, which components do you want to improve most? 


\section{References}

1. Shek DT, Yu L, Ma CM, Sun RC, Liu TT. Development of a creditbearing service leadership subject for university students in Hong Kong. Int J Adolesc Med Health 2013;25:353-61.

2. Hong Kong Institute of Service Leadership and Management. SLAM education, 2013. Available at: http://hki-slam.org/

3. Yukl G. Leadership in organizations, 6th ed. Upper Saddle River, NJ: Pearson-Prentice Hall, 2006.

4. Northouse PG. Leadership: theory and practice, 5th ed. London: Sage, 2010.

5. Chung P. Service reborn. New York: Lexingford Publishing, 2012.

6. Strother JB, Grofeldt S. Service leadership: the challenge of developing a new paradigm. Proceedings of IEEE Professional Communication Conference; 2005 Jul 10-13. IEEE, 2005: 65-71.

7. Schneider B, Ehrhart MG, Mayer DM, Saltz JL, Niles-Jolly K. Understanding organization-customer links in service settings. Acad Manage J 2005;48:1017-32.

8. Farrell AM, Souchon AL. The service leadership scale: a substantive validity test. In: Australia and New Zealand Marketing Academy Conference 2003 Dec 1-3; Adelaide, Australia, University of Auckland Business School, 2003:1-7.

9. Greenleaf RK. Servant-leadership: a journey into the nature of legitimate power and greatness. New York: Paulist Press, 1977.

10. Van Dierendonck D. Servant leadership: a review and synthesis. J Manage 2011;37:1228-61.

11. Brown ME, Treviño LK. Ethical leadership: a review and future directions. Leadership Quart 2006;17:595-616.

12. Bass BM. Current developments in transformational leadership. Psychologist-Manag J 1999;3:5-22.

13. Fry LW. Toward a theory of spiritual leadership. Leadership Quart 2003;14:693-727.

14. Russell RF. The role of values in servant leadership. Leader Organ Dev J 2001;22:76-84.

15. Emiliani ML. Linking leaders' beliefs to their behaviors and competencies. Manag Decis 2003;41:893-910.

16. Stone AG, Russell RF, Patterson K. Transformational versus servant leadership: a difference in leader focus. Leader Organ Dev J 2004;25:349-61.

17. Rost JC, Barker RA. Leadership education in colleges: toward a 21st century paradigm. J Leader Organ Stud 2000; 7:3-12.

18. Román S, Ruiz S. Relationship outcomes of perceived ethical sales behavior: the customer's perspective. J Bus Res 2005;58:439-45.

19. Yieh K, Chiao YC, Chiu YK. Understanding the antecedents to customer loyalty by applying structural equation modeling. Total Qual Manage Bus Excel 2007;18:267-84.
20. Kalshoven K, Den Hartog DN. Ethical leader behavior and leader effectiveness: the role of prototypicality and trust. IJLS 2009;5:102-20.

21. Mahsud R, Yukl G, Prussia G. Leader empathy, ethical leadership, and relations-oriented behaviors as antecedents of leadermember exchange quality. J Manag Psychol 2010;25:561-77.

22. Zhu W, May DR, Avolio BJ. The impact of ethical leadership behavior on employee outcomes: the roles of psychological empowerment and authenticity. J Leader Organ Stud 2004;11:16-26.

23. Galton F. Hereditary genius. New York: Appleton, 1869.

24. Hogan R, Kaiser RB. What we know about leadership. Rev Gen Psychol 2005;9:169-80.

25. Zaccaro SJ. Trait-based perspectives of leadership. Am Psychol 2007;62:6-16.

26. Haidt J, Joseph C. Intuitive ethics: how innately prepared intuitions generate culturally variable virtues. Daedalus 2004;133:55-66.

27. Sober E, Wilson DS. Unto others: the evolution and psychology of unselfish behavior. Cambridge, MA: Harvard University Press, 1999.

28. Molden DC, Dweck CS. Finding “meaning” in psychology. Am Psychol 2006;61:192-203.

29. Lucia AD, Lepsinger R. The art and science of competency models. San Francisco: Jossey-Bass, 1999.

30. Higgs $M$. How can we make sense of leadership in the 21st century? Leader Organ Dev J 2003;24:273-84.

31. Spears LC. Reflections on leadership: how Robert K. Greenleaf's theory of servant-leadership influenced today's top management thinkers. New York, NY: John Wiley, 1995.

32. Russell RF, Stone AG. A review of servant leadership attributes: developing a practical model. Leaders Organ Dev J 2002;23:145-57.

33. Harter S. Authenticity. In: Snyder CR, Lopez S, editors. Handbook of positive psychology. Oxford, UK: Oxford University Press, 2002:382-94.

34. Tracey JB, Hinkin TR. Transformational leadership or effective managerial practices? Group Organ Manage 1998;23:220-36.

35. Avolio BJ, Walumbwa FO, Weber TJ. Leadership: current theories, research, and future directions. Annu Rev Psychol 2009;60:421-49.

36. Judge TA, Piccolo RF. Transformational and transactional leadership: a meta-analytic test of their relative validity. J Appl Psychol 2004;89:755-68.

37. Reave L. Spiritual values and practices related to leadership effectiveness. Leader Q 2005;16:655-87.

38. Dirks KT, Ferrin DL. Trust in leadership: meta-analytic findings and implications for research and practice. J Appl Psychol 2002;87:611-28.

39. Cohen SL. Effective global leadership requires a global mindset. Ind Commerc Train 2010;42:3-10. 